\title{
Characterization of bismuth-cerium-molybdate selective propylene ammoxidation catalysts
}

\author{
$\underline{\text { James F. Brazdil }}^{1}$, Mark A. Toft ${ }^{1}$, Sean S.-Y. Lin ${ }^{1}$, Stephen T. McKenna ${ }^{1}$, \\ Gerry Zajac ${ }^{1}$, James A. Kaduk ${ }^{2}$, Joseph T. Golab ${ }^{1}$ \\ ${ }^{1}$ INEOS Technologies, Naperville, IL 60563 USA \\ ${ }^{2}$ Poly Crystallography Inc., Naperville, IL 60540 USA and Department of Biological and Chemical \\ Sciences, Illinois Institute of Technology, Chicago IL 60616 USA
}

\begin{abstract}
Acrylonitrile is a major chemical intermediate used in the production of a wide range of chemical and polymer products. Central to the commercial process is a proprietary catalyst consisting of a complex mixture of metal oxides containing a bismuth-containing molybdate phase that is active and selective for propylene ammoxidation to acrylonitrile. Among the most active and selective is a solid solution of bismuth and cerium molybdate. Solid state structural studies were undertaken to characterize this active phase. The results show that the mixed bismuth-cerium molybdate consists of a solid solution phase having the scheelite-related structure of cerium molybdate with a monoclinic unit cell. Analysis of the cation site occupancy using synchrotron X-ray diffraction indicates that bismuth preferentially occupies the $\mathrm{Ce}(3)$ site of the monoclinic cerium molybdate structure. It is therefore possible to singularly identify the structure of the active site for propylene ammoxidation given that bismuth is a necessary constituent of a site for selective propylene (amm)oxidation. The proposed active site consists of bismuth located next to a cation vacancy in the structure, presumably in order to accommodate its lone pair of electrons. Bismuth serves as the site for the rate determining $\alpha$-hydrogen abstraction from propylene to form an allyl intermediate and subsequent nitrogen insertion and loss of lattice oxygen. The bismuth site is surrounded by two cerium cations in this active site configuration. Thus the model that emerges from this study is $\mathrm{Bi}^{3+}$ and $\mathrm{Ce}^{3+}$ in a molybdate structural framework with cerium readily able to undergo $\mathrm{Ce}^{3+} \leftrightarrow \mathrm{Ce}^{4+}$ redox that facilitates lattice oxygen transfer to the active site as required by the operative Mars-van Krevelen mechanism for selective propylene ammoxidation. The presence of two cerium cations adjacent to bismuth as a key component of the active site is expected to promote the rapid re-oxidation of the catalytic site effecting enhanced catalytic performance with respect to selective product yields and productivity.
\end{abstract}


Graphical abstract: Proposed model of active sites for propylene ammoxidation in bismuthcerium molybdate catalyst having the cerium molybdate structure.

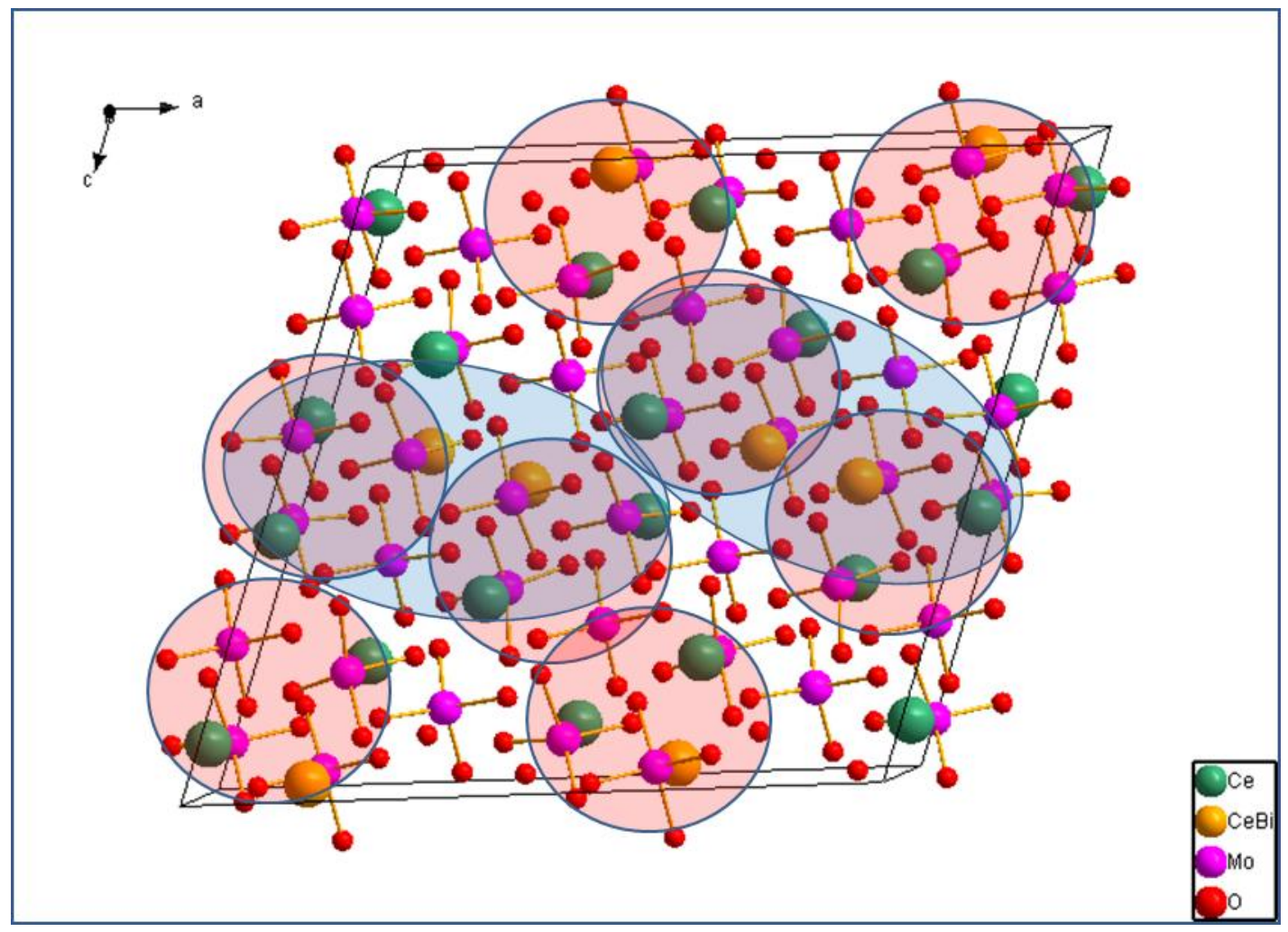


Keywords:

propylene ammoxidation, bismuth-cerium-molybdate catalyst, bismuth-cerium molybdate solid solution, scheelite-derived structures 


\section{Introduction}

Acrylonitrile is produced by the so-called SOHIO Process which is the catalyzed gas phase reaction of propylene, ammonia and air in a fluid-bed reactor [1]. The process was discovered, patented [2] and commercialized in the first plant in Lima Ohio in 1960. Acrylonitrile is produced in plants world-wide using the original SOHIO Process based on selective propylene ammoxidation catalysis. This process is unique in that it uses a fluid-bed reactor and catalyst rather than a fixed-bed reactor used in the vast majority of other chemical processes. The remarkable early, and the most recent, growth in commercial application of the SOHIO acrylonitrile process has coincided with the development of generation upon generation of new catalyst families. Each new generation of catalyst further increases the acrylonitrile yield and overall process efficiency. Future demand for acrylonitrile necessitates that new strategies be developed to further improve the yield of useful nitrile products from this process. Our approach is to enable these improvements through a deeper fundamental understanding of the chemistry of mixed metal oxides capable of catalyzing the operative Mars-van-Krevelen mechanism [3] for selective oxidation of olefins.

The discovery of the first selective propylene oxidation and ammoxidation catalyst based on bismuth molybdate initiated a completely new field for technology development and catalyst design [4]. Multiple generations of catalysts were created and commercialized in the ensuing years. All these molybdate-based catalysts had one critical feature in common; the active phase for the transformation of propylene to acrolein or acrylonitrile (in the presence of ammonia) is the $\alpha-\mathrm{Bi}_{2} \mathrm{Mo}_{3} \mathrm{O}_{12}$ phase, the same principal constituent of the very first commercial acrylonitrile catalyst.

Recently we have undertaken a study of single phase bismuth-cerium-molybdate which has a unique scheelite-derived structure that is a marked departure of the bismuth molybdate active phase present in the early generations of acrylonitrile catalysts. The bismuth-cerium molybdate compound was first discovered as an effective catalyst for propylene ammoxidation in the 1980s [5]. Earlier structural and chemical characterization of the bismuth-cerium molybdate compound was based largely on powder Xray diffraction patterns indexed using the bismuth molybdate and cerium molybdate structure types [68]. A rudimentary phase diagram was constructed based on these results with the conclusion that two solid solutions exist across the compositional space $\mathrm{Bi}_{\mathrm{x}} \mathrm{Ce}_{2-\mathrm{x}} \mathrm{Mo}_{3} \mathrm{O}_{12}$ with $0 \leq \mathrm{x} \leq 2$. One solid solution consists of cerium dissolved in the $\alpha-\mathrm{Bi}_{2} \mathrm{Mo}_{3} \mathrm{O}_{12}$ structure for $\mathrm{x}$ greater than about 1.8. The second solid solution having bismuth dissolved in the cerium molybdate structure when $\mathrm{x}$ is less than about one.

The implicit assumption in this earlier work was that the trivalent cation distribution in the solid solutions was statistically random with the bismuth and cerium cations distributed across all the trivalent cation sites of the scheelite-derived structure [9]. The analysis at the time did not determine if any crystallographic specificity exists for the occupancy of the trivalent cation sites.

The work described herein is an effort to focus on the cerium-rich region of the bismuth-ceriummolybdate phase diagram. This represents bismuth in a different coordination sphere in a scheelitederived structure compared to its naturally occurring environment in $\alpha-\mathrm{Bi}_{2} \mathrm{Mo}_{3} \mathrm{O}_{12}$ or in the other known bismuth molybdate compound, $\gamma-\mathrm{Bi}_{2} \mathrm{MoO}_{6}$. This unique environment for bismuth, which is the necessary component of the catalyst for activation of propylene to form the allyl intermediate that transforms to acrylonitrile, is likely a major factor responsible for the enhanced activity and selectivity of the catalysts discussed above. To this end, a further solid state and surface structural characterization of this cerium-rich bismuth molybdate solid solution was undertaken to understand the nature of the active phase of a new generation of acrylonitrile catalysts. 


\section{Experimental}

\subsection{Bismuth-cerium-molybdenum oxide preparation}

The catalysts were prepared by co-precipitation method. Aqueous solutions prepared with $\left(\mathrm{NH}_{4}\right)_{6} \mathrm{Mo}_{7} \mathrm{O}_{24} \bullet 4 \mathrm{H}_{2} \mathrm{O}$, Bi( $\left(\mathrm{NO}_{3}\right)_{3} \cdot 5 \mathrm{H}_{2} \mathrm{O}$, and $\left(\mathrm{NH}_{4}\right)_{2} \mathrm{Ce}\left(\mathrm{NO}_{3}\right)_{6}$ were mixed sequentially at room temperature to form a slurry followed by addition of $\mathrm{NH}_{4} \mathrm{OH}$ to adjust the slurry $\mathrm{pH}$. In addition, 50 wt.\% ammonium-stabilized silica sol was added into selected slurries to form supported catalysts. Conventionally silica sol was added to increase the hardness of the catalysts. The slurries were evaporated in a vacuum oven or spray-dried to form dry powders followed by calcination in a muffle furnace. The catalysts were calcined at $290^{\circ} \mathrm{C}$ for $3 \mathrm{~h}$, followed by $425^{\circ} \mathrm{C}$ for $3 \mathrm{~h}$, and finally $560^{\circ} \mathrm{C}$ for $3 \mathrm{~h}$. For selected catalysts, extended heating at $560^{\circ} \mathrm{C}$ or $600^{\circ} \mathrm{C}$ was applied. The compositions of all catalysts were confirmed by elemental analysis using inductively coupled plasma (ICP) analysis with acid digestion of the samples.

\subsection{Catalyst characterization}

\subsubsection{X-ray diffraction (XRD)}

Laboratory X-ray diffraction analyses were performed on a Bruker D8 Advance powder diffractometer equipped with a Vantec-1 position-sensitive detector, and a Panalytical X'Pert Pro MPD powder diffractometer with a PIXcel position-sensitive detector, both using $\mathrm{Cu} \mathrm{K} \alpha$ radiation (wavelength $1.54063 \AA$ ). Samples were mounted in a flat plate geometry, either by sprinkling the powdered sample onto double-sided tape affixed to a quartz zero-background cell, or by packing the powder into a cup-shaped cell. XRD scans were collected at room temperature from $5^{\circ}$ to $100^{\circ}$ twotheta over a period of 8 hours, with sample spinning where possible.

Temperature-programmed XRD experiments were performed on the Panalytical diffractometer using an Anton Paar HTK1200N furnace accessory and Anton Paar TCU1000N temperature controller. Samples were packed into a corundum cup and placed in a stationary mount in the center of the furnace. X-rays enter and exit the furnace through aluminum-coated Kapton windows. A steady flow of air through the furnace was maintained at about $1 \mathrm{scfh}$. Heating was at $10^{\circ} \mathrm{C} / \mathrm{min}$, followed by $10 \mathrm{~min}$ for equilibration, and then a 4 hour XRD scan $\left(5^{\circ}-100^{\circ}\right.$ two-theta); cooling was at $5^{\circ} \mathrm{C} / \mathrm{min}$.

Synchrotron XRD studies were conducted on beamline 11-BM [10,11] of the Advanced Photon Source at Argonne National Laboratory under proprietary General User Proposal 34857. Samples were packed into $0.8 \mathrm{~mm}$ diameter Kapton capillaries, and rotated during the experiment at 50 rps. XRD scans were collected using a wavelength of $0.413897 \AA$ at $300^{\circ} \mathrm{K}$ from $0.5^{\circ}-50^{\circ}$ two-theta over a period of 82 minutes.

XRD patterns were analyzed by the Rietveld method using GSAS software [12,13].

\subsubsection{Electron microscopy}

A Zeiss Leo 1530 scanning electron microscope (SEM) with a field emission gun was utilized for the imaging of the acrylonitrile model catalysts equipped with a Bruker Xflash 5030 Energy Dispersive spectroscopy and silicon drift detector for microanalysis. The samples were coated with $\sim 30 \AA$ of Au in order to minimize charging of the sample surface for imaging and to minimize interference of emissions 
with the $\mathrm{Bi} \mathrm{M}_{\alpha}$ and $\mathrm{Bi} \mathrm{L}_{\alpha}$ edges. The ACAT (Aberration Corrected TEM $-\mathrm{C}_{\mathrm{C}}, \mathrm{C}_{\mathrm{S}}$ ) at the electron microscopy center at Argonne National Lab was employed for the transmission electron microscopy.

\subsubsection{X-ray absorption near edge structure (XANES)}

The X-ray absorption near edge structure (XANES) was performed at beamline 10-BM at the Advanced Photon Source (APS) at Argonne National Laboratory. Two standards were employed for the $\mathrm{Ce}^{3+}\left(\mathrm{Ce}_{2} \mathrm{~S}_{3}\right)$ and $\mathrm{Ce}^{4+}\left(\mathrm{CeO}_{2}\right)$ with $\mathrm{L}$ edge positions at $5.7250 \mathrm{keV}(0.0027 \mathrm{keV}$ lower energy relative to $\mathrm{Ce}^{4+}$ ) and $5.7277 \mathrm{keV}$, respectively. The XANES were obtained in transmission mode to reflect the bulk composition of the samples and model catalysts Ineos-03 and Ineos-04. The XANES spectra were obtained over the energy range from $5.710-5.760 \mathrm{keV}$ in order to observe the near edge structure primarily.

\subsubsection{X-ray photoelectron spectroscopy (XPS)}

The X-ray photoelectron spectroscopy (XPS) was performed on a Perkin-Elmer (PE) (PHI) 5802 spectrometer with a monochromatized $\mathrm{Al} \mathrm{K} \mathrm{K}_{\alpha}$ source with photon energy of $1486 \mathrm{eV}$. The PE MultiPak v5.0A software is utilized to analyze the data and provide curve fitting.

The heat treatments prior to XPS analysis are performed ex-situ in a tube furnace either in ambient lab air for calcination at $560-600{ }^{\circ} \mathrm{C}$ or in flowing dehydrated house $\mathrm{N}_{2}$. Ramp up to temperature and cool down are preformed over 1-2 hours and in the case of $\mathrm{N}_{2}$ treatment room temperature is achieved before removal from the flowing $\mathrm{N}_{2}$ source. Rapid transfer to the XPS introduction system is performed with pump down occurring over a few minutes via a turbo-molecular pump. Exposure to ambient lab air is minimized by transferring in a $\mathrm{N}_{2}$ filled container between the furnace and XPS introduction system. The determination of the percentage of $\mathrm{Ce}^{3+, 4+}$ oxidation states of was performed according to a recent method [14] to quantitate the two oxidation states of Ce.

\subsubsection{Fourier transform infrared spectroscopy (FTIR)}

Infrared spectra of unsupported catalysts were collected by adding 128 scans of 4,000-400 $\mathrm{cm}^{-1}$ with a resolution of $4 \mathrm{~cm}^{-1}$, using a Thermo Nicolet 380 FTIR spectrometer with a SmartOrbit diamond attenuated total reflectance (ATR) accessory.

\subsubsection{Modeling}

Periodic Density Functional Theory (DFT) results are obtained by the ab-initio total-energy and molecular-dynamics package VASP (Vienna ab-initio Simulation Package) developed at the Institut für Materialphysik of the Universität Wien [15,16] as implemented in the MedeA® (Materials Exploration and Design Analysis, a registered trademark of Materials Design, Inc., Angel Fire, New Mexico, USA, 2014) v2.14 software environment. VASP (v5.3) is a world leading first-principles solid state electronic structure program for solids, surfaces, and interfaces [17]. Possessing a comprehensive array of advanced features, including hybrid functionals, the ability to incorporate dispersion interactions, and comprehensive and validated self-consistent PAW potentials, VASP is an effective application for the calculation of electronic properties of industrially important solid state materials. Each calculation is a full geometry optimization, i.e. atom positions and unit cell shape and volume, to a convergence energy criterion of 1.0E-05 eV utilizing real space projection operators for computational speed. The VASP 
input parameters include the GGA-PBE exchange-correlation functional for describing the interactions and GGA-PBE / PAW potentials for all atoms. The k-spacing varied per model calculation but typical $\mathrm{k}$-mesh is $1 \times 1 \times 1$ for scheelite models and forced to be centered on the gamma point. A default planewave cutoff energy of $400.0 \mathrm{eV}$ is uniformly applied and, to help convergence, Gaussian smearing is used with a typical width of $0.2 \mathrm{eV}$. Due to magnetic moments in some of the models, calculations are spin-polarized using normal precision criteria.

The initial model of the monoclinic scheelite with empirical formula $\mathrm{Mo}_{36} \mathrm{Ce}_{24} \mathrm{O}_{144}$ (so-called $\mathrm{Bi0}$ ) is based on the Jeitschko $\mathrm{Ce}_{2} \mathrm{Mo}_{3} \mathrm{O}_{12}$ experimental structure [9]. Starting from the $\mathrm{Bi0}$ structure, another structure is created by replacing each cerium atom at a $\mathrm{Ce}(3)$ symmetry site with a bismuth atom resulting in the formula $\mathrm{Mo}_{36} \mathrm{Ce}_{16} \mathrm{Bi}_{8} \mathrm{O}_{144}$ (so-called $\mathrm{Bi} 8$ ). Other monoclinic scheelite unit cells are created in the same way, e.g. Bi6 in which six random $\mathrm{Ce}(3)$ cerium atoms are replaced with bismuth atoms and $\mathrm{Bi} 12$ in which all eight $\mathrm{Ce}(3)$ cerium atoms and four random $\mathrm{Ce}(1)$ site symmetry cerium atoms are replaced with bismuth atom.

\section{Results and Discussion}

As was described by Brixner et al. [18], the incorporation of a trivalent cation in the divalent cation site of normal scheelite (empirical formula $\mathrm{ABO}_{4}$, based on $\mathrm{CaWO}_{4}$ ) produces a defect structure containing cation vacancies needed for electro-neutrality. The primitive scheelite unit cell is tetragonal, but a trivalent scheelite crystallizes in a superstructure featuring several (typically 3 or 9) primitive scheelite unit cells arranged in a supercell with monoclinic symmetry. The resulting monoclinic structure has large cation sites distinguished by a local environment that consists of vacant cation sites as well as other large cations. The key features of the primitive scheelite unit cell and the monoclinic superstructure found in cerium molybdate are:

- The primitive scheelite structure is tetragonal (space group $\mathrm{I} 4_{1} / \mathrm{a}$ ). The empirical formula is $\mathrm{ABO}_{4}$, where $\mathrm{A}^{2+}$ is a large cation which is 8 -coordinated by oxygen, and $\mathrm{B}^{6+}$ is a small cation which is tetrahedrally coordinated by oxygen. There are 4 such formula units in the unit cell.

- Substitution of the divalent cation by a trivalent cation results in a defect scheelite structure wherein $\mathrm{A}$ is now a $3+$ large cation and the empirical formula is $\mathrm{A}_{2} \square\left(\mathrm{BO}_{4}\right)_{3}$, where $\square$ indicates a vacancy.

- In the case of cerium molybdate, nine primitive scheelite unit cells are arranged in a supercell which contains $12 \mathrm{~A}_{2} \square\left(\mathrm{BO}_{4}\right)_{3}$ formula units. The defect structure retains the scheelite packing arrangement, with one-third of the large cation sites vacant. The cations and cation vacancies are ordered, and there are three non-equivalent $\mathrm{A}^{3+}$ cation sites designated $\mathrm{Ce}(1), \mathrm{Ce}(2)$, and $\mathrm{Ce}(3)$, and there are eight instances of each of these sites in the supercell. There are two non-equivalent cation vacancy sites, one occurs in eight locations in the supercell and the other, which falls on a special position, occurs in four locations. The resulting superstructure is monoclinic (space group $\mathrm{C} 2 / \mathrm{c})$.

Of note is that when the A cation is cerium there exists optionality for multiple oxidation state $\left(\mathrm{Ce}^{3+} /\right.$ $\left.\mathrm{Ce}^{4+}\right)$.

Figure 1 shows the $\mathrm{X}$-ray diffraction pattern for the $\mathrm{Bi}_{0.5} \mathrm{Ce}_{1.5} \mathrm{Mo}_{3} \mathrm{O}_{12}$ composition. The pattern can be indexed to the monoclinic cerium molybdate structure and Rietveld analysis shows the phase purity to be essentially $100 \%$. The figure compares the diffraction patterns obtained from a laboratory X-ray diffractometer and from a synchrotron X-ray source. The latter clearly provides the highest quality data, allowing the best overall pattern fit, including in the critical low angle region. This region of the diffraction pattern provides the critical information about the superstructure, as shown in Figure 2. 
Rietveld analysis was applied to the diffraction patterns across the series $\mathrm{Bi}_{\mathrm{x}} \mathrm{Ce}_{2-\mathrm{x}} \mathrm{Mo}_{3} \mathrm{O}_{12}, 0 \leq \mathrm{x} \leq 2$ for the first time in order to quantify the phase composition. Figure 3 summarizes the results for this series when heat treated at $560^{\circ} \mathrm{C}$ which shows the phase composition moving from a solid solution of bismuth in the $\mathrm{Ce}_{2} \mathrm{Mo}_{3} \mathrm{O}_{12}$ structure for $\mathrm{x}$ less than about 0.8 through a two phase region of bismuth molybdate and cerium molybdate solid solutions for $\mathrm{x}$ between about 0.8 and about 1.8. This is consistent with our earlier work confirming a broad composition range for bismuth in cerium molybdate and a much narrower range for cerium in $\alpha$-bismuth molybdate. Furthermore, in the cerium molybdate phase region, the monoclinic unit cell volume decreases monotonically with increasing bismuth content. This trend in cell volume is consistent with the existence of a solid solution bismuth-cerium molybdate. The decrease in cell volume with increasing bismuth content further indicates that bismuth is acting crystallographically as a smaller cation than cerium which means it is likely situated in a local site environment that produces little or no spatial attenuation from its lone pair of electrons. In other words, the site or sites in the cerium molybdate structure that bismuth occupies must be able to spatially accommodate the bismuth lone pairs. When bismuth forms solid solutions in other structures in which the cation site cannot fully accommodate the lone pair, bismuth acts as a large cation and results in an increase in unit cell volume [19].

The FTIR analysis (Figure 4) of this series supports the interpretation of a continuous change from the $\mathrm{Ce}_{2} \mathrm{Mo}_{3} \mathrm{O}_{12}$ with low bismuth content to the appearance of the characteristic bands assigned to $\alpha$ $\mathrm{Bi}_{2} \mathrm{Mo}_{3} \mathrm{O}_{12}$ as the bismuth content increases. This supports X-ray diffraction interpretation that phase segregation occurs when the bismuth content exceeds about $50 \%$ of the cerium cation site.

As shown in Fig.4, absorption peaks at 528, 825, 901, and $931 \mathrm{~cm}^{-1}$, which begin to emerge in $\mathrm{Bi}_{\mathrm{x}} \mathrm{Ce}_{2-\mathrm{x}} \mathrm{Mo}_{3} \mathrm{O}_{12}$ when $\mathrm{Bi}$ content exceeds $\mathrm{x}=1$, are associated with $\mathrm{Bi}_{2}\left(\mathrm{MoO}_{4}\right)_{3}$. An FTIR spectrum of $\mathrm{Bi}_{2}\left(\mathrm{MoO}_{4}\right)_{3}$ obtained from Alfa Aesar showed identical peaks, supporting the presence of $\mathrm{Bi}_{2}\left(\mathrm{MoO}_{4}\right)_{3}$ phase in these materials. These peaks were attributed to the vibrations of distorted $\left(\mathrm{MoO}_{4}\right)^{2-}$ tetrahedral groups [20-22]. Finally, the peaks at 700, 804, and $914 \mathrm{~cm}^{-1}$ rapidly disappeared as Bi content exceeds $\mathrm{x}$ $=1$, suggesting these vibrations are associated with the distortion of tetrahedral $\left(\mathrm{MoO}_{4}\right)^{2-}$ in $\mathrm{Ce}_{2}\left(\mathrm{MoO}_{4}\right)_{3}$ scheelite phase $[23,24]$.

It is possible to prepare phase-pure $\mathrm{Bi}_{0.5} \mathrm{Ce}_{1.5} \mathrm{Mo}_{3} \mathrm{O}_{12}$ by heat treatment of the co-precipitated precursor at $560^{\circ} \mathrm{C}$ and $600^{\circ} \mathrm{C}$ as shown in Table 1 . However, extended heat treatment times at $600^{\circ} \mathrm{C}$ result in oxidation of some decomposition due to oxidation of $\mathrm{Ce}^{3+}$ to $\mathrm{Ce}^{4+}$ and the formation of $\mathrm{CeO}_{2}$. The presence of silica support, which is required for a commercial catalyst to provide strength and attrition resistance in fluid-bed reactor operation, does not have a significant impact on phase formation or phase purity.

Figure 5 shows the evolution of the bismuth-cerium molybdate phase from the poorly understood precursor state to the crystalline monoclinic phase with increasing temperature. This is manifest from the distinct presence by $500^{\circ} \mathrm{C}$ heat treatment temperature of intense primitive scheelite diffraction peaks $\left(28^{\circ}-34^{\circ}\right.$ and $\left.46^{\circ}-58^{\circ}\right)$, plus the weaker low-angle $\left(10^{\circ}-25^{\circ}\right)$ superstructure diffraction peaks which are a fingerprint for the defect monoclinic phase.

The XANES spectra obtained at $10-\mathrm{BM}$ for the two $\mathrm{Ce}^{3+, 4+}$ oxidation state standards and model catalyst samples Ineos-03 and -04 are shown in Figure 6. The XANES analysis reveals that the transformation observed by temperature programed XRD above $500^{\circ} \mathrm{C}$ also involves a change in the cerium oxidation from $4+$ in the precursor material to $3+$ in the bismuth-cerium molybdate phase. Since XANES is a bulk measurement and not surface sensitive, it shows that the bulk structure of the bismuthcerium molybdate phase is based on cerium being in the $3+$ oxidation state. However, analysis of the cerium oxidation state on the surface by XPS (Table 2) reveals that a portion of cerium is oxidized to the $4+$ oxidation. Thus under ambient conditions, about a third of the cerium is in the $4+$ oxidation state. It 
is not uncommon in the case of multivalent metal oxides to have the metal at the surface in multiple oxidation states depending on the gas phase composition and temperature. This is in fact a crucial requirement of effective metal oxide selective oxidation catalysts which must undergo facile redox at the surface where the active site undergoes reduction during catalytic activation during the hydrocarbon reaction while the bulk must be able transport oxygen ions from the lattice to the active site. The fact that cerium exhibits multiple oxidation states at the surface of $\mathrm{Bi}_{0.5} \mathrm{Ce}_{1.5} \mathrm{Mo}_{3} \mathrm{O}_{12}$ is an excellent indicator that this prototypal active phase likely serves extremely well for selective hydrocarbon oxidation via the Mars-van Krevelen mechanism, and certainly better than the $\alpha-\mathrm{Bi}_{2} \mathrm{Mo}_{3} \mathrm{O}_{12}$ phase which is the active component of the earliest generations of commercial acrylonitrile catalysts.

Focusing on the synchrotron X-ray diffraction data, we were able to obtain an excellent Rietveld refinement using the monoclinic cerium molybdate structure. Figure 7 shows the fit of the diffraction pattern, with the difference between observed and calculated patterns shown at the bottom. The analysis confirms the presence of single phase monoclinic bismuth-cerium-molybdate, but the relatively poorer fit of the low angle diffraction lines suggests that the representation of the solid solution as having the ideal cerium molybdate structure, though mostly sufficient, may not be exactly right. The poorer fit of the superstructure lines may be due to other defects in the structure. One possibility is that some of the vacancy sites may be partially filled randomly throughout the structure. It is not, however, possible from the data to determine this with any certainty. Either analysis of a single crystal by X-ray diffraction and/or powder neutron diffraction to locate the oxygen atoms in the structure is needed to better refine the complete structure.

Table 3 lists the details from the Rietveld fitting of the synchrotron X-ray diffraction data for $\mathrm{Bi}_{0.5} \mathrm{Ce}_{1.5} \mathrm{Mo}_{3} \mathrm{O}_{12}$. Firstly, the high quality of the synchrotron data results in more precise determination of lattice parameters, which are consistent across all the phase-pure samples. The added piece of information obtained from the refinement is the determination, with a high degree of confidence, that bismuth preferentially occupies one of the three specific cation sites in the $\mathrm{La} / \mathrm{Ce}$ molybdate structure. Crystallographically, this site is designated $\mathrm{Ce}(3)$ in the $\mathrm{La} / \mathrm{Ce}$ molybdate structure. Therefore compared to our earlier work, this current analysis indicates that the bismuth-cerium molybdate phase may not be a conventional solid solution. For an ideal solid solution, bismuth would be expected to be present on all cation sites. Instead bismuth exhibits a site preference in this structure based on the cation occupancy determination from Rietveld analysis.

Computational modeling of bismuth incorporation into an ideal cerium molybdate structure supports a preference for the $\mathrm{Ce}(3)$ site. Table 4 summarizes the calculated energies relative to the $\mathrm{Ce}(3)$ site for bismuth atom to replace cerium atom in each of the three cerium symmetry sites in the structure. Bismuth in the $\mathrm{Ce}(3)$ site is the lowest energy option among the three large cation sites in the structure. Additionally, from the optimized structures obtained for the modeling, simulated diffraction patterns from each independently fully optimized unit cell geometry for each composition were calculated and indexed to the cerium molybdate structure type. Based on these patterns, unit cell parameters were calculated. A plot of the calculated unit cell volumes are shown in Figure 8 compared to the experimentally determined values. These calculations add credence to representing the mixed bismuth cerium molybdate as a single phase material represented by the cerium molybdate structure type. The model supports the hypothesis that when bismuth enters the cerium molybdate structure, it acts as a smaller cation than cerium. Thus the coordination sphere for bismuth in the structure must accommodate the additional spatial requirement of its lone pair of electrons that cerium $3+$ does not have.

Further evidence for bismuth-cerium molybdate existing as a monoclinic defect scheelite phase is provided by the aberration corrected TEM analysis which is summarized in Figure 9. This TEM 
analysis supports the presence of a single phase which is the monoclinic phase identified by X-ray diffraction. This is apparent from the Moiré fringes which clearly show the obtuse angle characteristic of a monoclinic unit cell, as opposed to only 90 degree angles if a tetragonal unit cell were present. Thus, there was no indication of any other structure type such as tetragonal scheelite. Of further note is that only the monoclinic unit cell angle appears across the samples. This indicates that the bismuth-cerium molybdate phase preferentially exposes the ac plane of the unit cell. This is evidenced by the field emission SEM shown in Figures 10 and EDS maps of Figure 11 at 150kX. In Figure 10 the platy morphology is observed for the molybdate phase embedded in a matrix of silica. The silica phase is spherical, semi-fused and of the same spatial extent as the original silica sol. The flat platy morphology suggests a primary crystallographic direction such as the $(010-$ ac plane $)$. It is therefore entirely reasonable to suggest that it is the (010) crystal face that dominates the catalytic behavior of the mixed phase and it is this crystal face that contains the active sites for propylene ammoxidation.

The close correlation of the Mo, Ce and $\mathrm{Bi}$ composition maps in Figures 11 confirms the scheelite composition of $\mathrm{Bi}_{0.5} \mathrm{Ce}_{1.5} \mathrm{Mo}_{3} \mathrm{O}_{12}$. This is as expected given the solid solution nature of this phase. However, close inspection of the composite map shows that the $\mathrm{Ce}$ and $\mathrm{Bi}$ are not everywhere completely uniform in composition. Nevertheless, the vast majority of the regions exhibit good mixing of $\mathrm{Ce}$ and $\mathrm{Bi}$ within the small individual grains constituting the larger several thousand Angstrom size platelets. These larger structures should be aggregates of smaller grains since X-ray diffraction measures average diffracting grain sizes of $\sim 1000 \AA$.

\section{Conclusions}

In conclusion, it is possible to construct a view of the active site for the bismuth-cerium molybdate catalytic phase from the characterization results presented here as shown in Figure 12. A key outcome of this study is that the bismuth-cerium molybdate phase having the cerium molybdate structure is in fact a materially different structural environment for the bismuth-containing active site for propylene ammoxidation. Bismuth is, of course, a necessary constituent of a propylene (amm)oxidation catalyst as it represents the component responsible for the rate determining $\alpha$-hydrogen abstraction from propylene [25]. This local environment for bismuth in bismuth-cerium molybdate is different than what has previously been observed and studied in selective olefin oxidation and ammoxidation catalysts which are that of the known bismuth molybdate phases, most often the $\alpha-\mathrm{Bi}_{2} \mathrm{Mo}_{3} \mathrm{O}_{12}$ phase. Specifically it is possible to visualize a catalytically active center in which bismuth is able to accommodate its lone pair of electrons by being next to a vacant cation site. Bismuth is further able to enhance its function in the selective oxidation process by having a redox active element in a neighboring structural site that serves as a shuttle for lattice oxidation pursuant to the Mars-van-Krevelen mechanism. This is expected to promote reoxidation/reconstruction of the bismuth active site in the catalytic cycle. We see this model as representing the basis for a new class of selective olefin oxidation catalyst family. Among the potential enhancements are higher activity, yield, productivity and longer catalyst life and stability compared to current state-of-the art catalysts.

\section{Acknowledgements}

We wish to acknowledge Russell Cook, Dean Miller and Jeff Miller from Argonne National Laboratories (ANL), for their assistance in providing the Aberration Corrected Transmission Electron Microscopy and X-Ray Near Edge Structure (XANES). The electron microscopy was accomplished at

Page 10 of 26 
the Electron Microscopy Center at Argonne National Laboratory, a U.S. Department of Energy Office of Science Laboratory operated under Contract No. DE-AC02-06CH11357 by UChicago Argonne, LLC. 
Tables

Table 1. Summary of catalyst sample preparation.

\begin{tabular}{|c|c|c|c|c|}
\hline Sample & $\begin{array}{c}\mathbf{5 0} \mathbf{w t}_{\mathbf{\%}} \mathbf{S i O}_{\mathbf{2}} \\
\text { supported }\end{array}$ & Heat Treatment & $\mathbf{C 2 / c}(\mathbf{w t} \%)^{*}$ & $\mathbf{C e O}_{\mathbf{2}}(\mathbf{w t .} \%)^{*}$ \\
\hline INEOS-01 & no & $\mathbf{6 0 0}^{\circ} \mathbf{C} \mathbf{6 0}$ days & 97.9 & 2.1 \\
\hline INEOS-02 & no & $\mathbf{5 6 0}^{\circ} \mathbf{C ~ 3 8}$ hours & 100 & 0 \\
\hline INEOS-03 & yes & $\mathbf{5 6 0}^{\circ} \mathbf{C} \mathbf{2 4}$ hours & 100 & 0 \\
\hline INEOS-04 & yes & $\mathbf{6 0 0}^{\circ} \mathbf{C ~ 2 4}$ hours & 100 & 0 \\
\hline INEOS-05 & yes & $\mathbf{6 0 0}^{\circ} \mathbf{C ~ 9 0}$ days & 98.5 & 1.5 \\
\hline
\end{tabular}

* Monoclinic cerium molybdate structure, as determined by Rietveld analysis of laboratory X-ray diffraction analysis.

Table 2. X-ray photoelectron spectroscopy (XPS) of the composition $\mathrm{Bi}_{0.5} \mathrm{Ce}_{1.5} \mathrm{Mo}_{3} \mathrm{O}_{12}$ at various heat treatment conditions. $\mathrm{CeO}_{2}$ and $\mathrm{Ce}_{2} \mathrm{~S}_{3}$ are included.

\begin{tabular}{|c|c|c|c|}
\hline Sample & Heat Treatment & Ce (3+) & Ce (4+) \\
\hline INEOS-06 & $560^{\circ} \mathrm{C} 3 \mathrm{~h}$ & $67 \%$ & $33 \%$ \\
\hline INEOS-03 & $560^{\circ} \mathrm{C} 24 \mathrm{~h}$ & $72 \%$ & $29 \%$ \\
\hline INEOS-04 & $600^{\circ} \mathrm{C} 24 \mathrm{~h}$ & $70 \%$ & $30 \%$ \\
\hline $\mathrm{CeO}_{2}$ & $560^{\circ} \mathrm{C} 3 \mathrm{~h}$ & $0 \%$ & $100 \%$ \\
\hline $\mathrm{Ce}_{2} \mathrm{~S}_{3}$ & $600^{\circ} \mathrm{C} 6 \mathrm{~h} \mathrm{in} \mathrm{N}_{2}$ & $39 \%$ & $61 \%$ \\
\hline
\end{tabular}

Table 3. Summary of Rietveld refinement of synchrotron X-ray diffraction data.

\begin{tabular}{|c|c|c|c|c|c|c|c|c|}
\hline Sample & $\mathbf{a}(\AA)$ & $\mathbf{b}(\AA)$ & $\mathbf{c}(\AA)$ & $\begin{array}{c}\beta \text { in } \\
\text { degree }\end{array}$ & $\begin{array}{c}\text { Bi:Ce at } \\
\text { Ce(1) } \\
\text { site }\end{array}$ & $\begin{array}{c}\text { Bi:Ce at } \\
\text { Ce(2) } \\
\text { site } \\
\end{array}$ & $\begin{array}{c}\text { Bi:Ce at } \\
\mathrm{Ce}(3) \\
\text { site } \\
\end{array}$ & $\begin{array}{c}\text { cell } \\
\text { volume } \\
\left(\AA^{3}\right) \\
\end{array}$ \\
\hline $\begin{array}{c}\text { INEOS- } \\
01\end{array}$ & $16.8665(1)$ & $11.8565(4)$ & $15.9602(1)$ & $108.665(1)$ & $\begin{array}{c}0.038: \\
0.962(4)\end{array}$ & $0: 1$ & $\begin{array}{c}0.247: \\
0.753(4)\end{array}$ & $3023.82(1)$ \\
\hline $\begin{array}{c}\text { INEOS- } \\
02 \\
\end{array}$ & $16.8641(2)$ & $11.8539(6)$ & $15.9664(2)$ & $108.660(1)$ & $0: 1$ & $0: 1$ & $\begin{array}{c}0.145: \\
0.855(5)\end{array}$ & $3023.97(2)$ \\
\hline $\begin{array}{c}\text { INEOS- } \\
03\end{array}$ & $16.8748(2)$ & $11.8373(7)$ & $15.9791(2)$ & 108.674(1) & $0: 1$ & $0: 1$ & $\begin{array}{c}0: 214: \\
0.786(6)\end{array}$ & $3023.83(4)$ \\
\hline $\begin{array}{c}\text { INEOS- } \\
04\end{array}$ & $16.8758(2)$ & $11.8391(6)$ & $15.9777(2)$ & $108.675(1)$ & $0: 1$ & $0: 1$ & $\begin{array}{c}0.199: \\
0.801(5)\end{array}$ & $3024.19(3)$ \\
\hline $\begin{array}{l}\text { INEOS- } \\
05\end{array}$ & $16.8762(2)$ & $11.8402(4)$ & $15.9742(9)$ & $108.679(1)$ & $0: 1$ & $0: 1$ & $\begin{array}{c}0.222: \\
0.778(4)\end{array}$ & $3023.79(2)$ \\
\hline
\end{tabular}


Table 4. Calculated relative energies of bismuth in monoclinic $\mathrm{Ce}_{2} \mathrm{Mo}_{3} \mathrm{O}_{12}$ structure

\begin{tabular}{|c|c|}
\hline Bismuth Location in $\mathbf{C e}_{\mathbf{2}} \mathbf{M o}_{\mathbf{3}} \mathbf{O}_{\mathbf{1 2}}$ structure & Relative $\boldsymbol{\Delta} \boldsymbol{\Delta E}(\mathbf{k c a l} / \mathbf{m o l})$ \\
\hline Bi occupying all $\mathrm{Ce}(1)$ sites & 1.69 \\
\hline Bi occupying all $\mathrm{Ce}(2)$ sites & 6.34 \\
\hline Bi occupying all $\mathrm{Ce}(3)$ sites & 0.00 \\
\hline
\end{tabular}




\section{Figures}

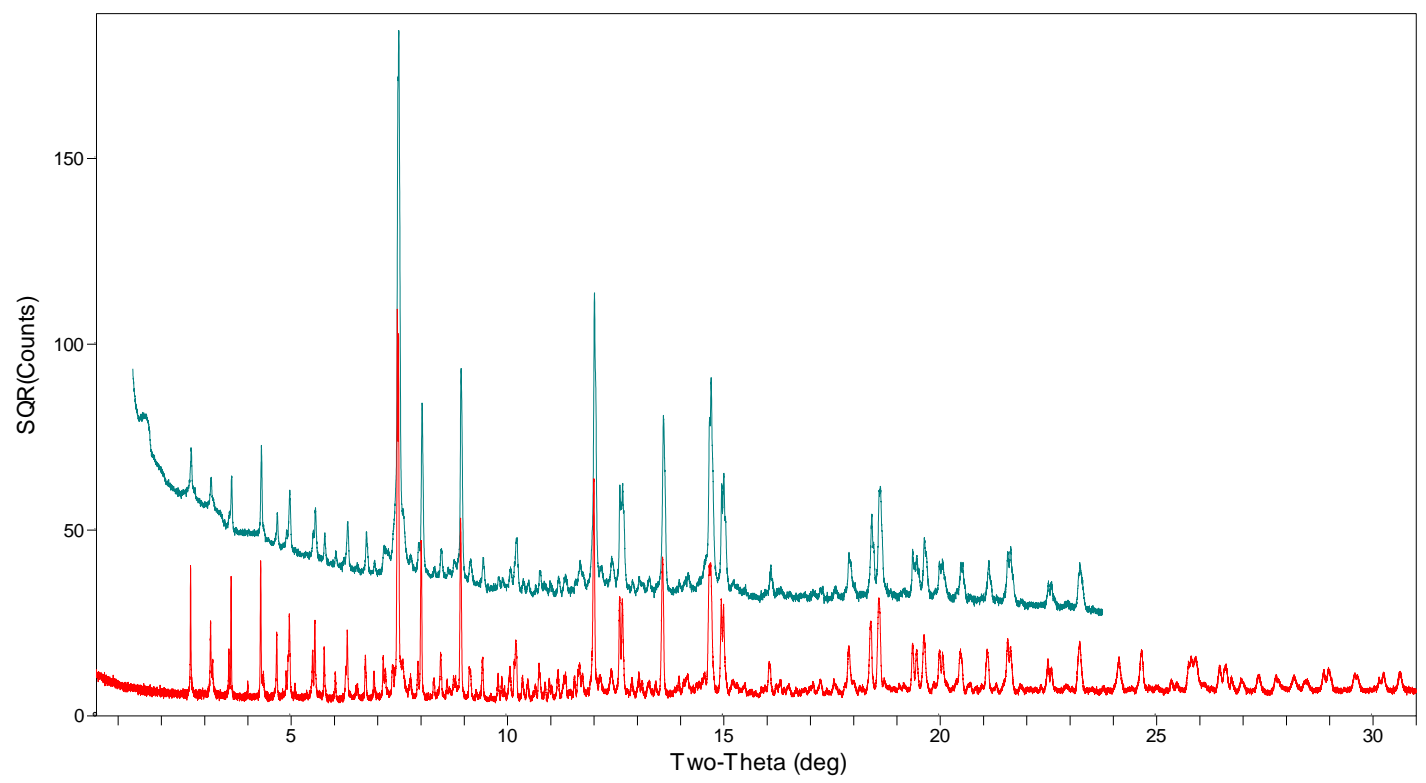

Figure 1. $\mathrm{X}$-ray diffraction patterns of the composition $\mathrm{Bi}_{0.5} \mathrm{Ce}_{1.5} \mathrm{Mo}_{3} \mathrm{O}_{12}$. Top pattern is from laboratory X-ray diffractometer and bottom pattern is using synchrotron X-ray source. 


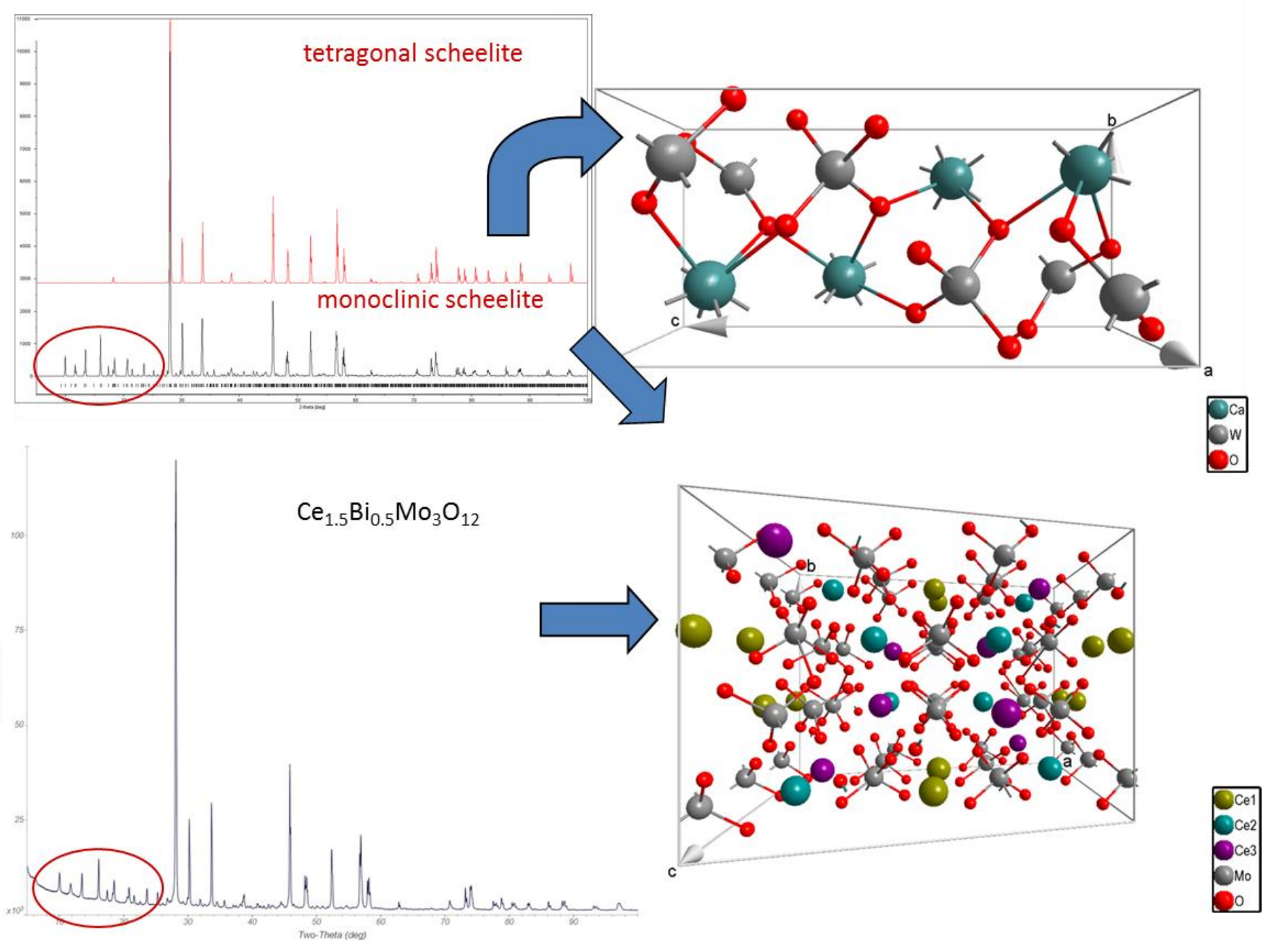

Figure 2. X-ray diffraction analysis of $\mathrm{Bi}_{0.5} \mathrm{Ce}_{1.5} \mathrm{Mo}_{3} \mathrm{O}_{12}$. 


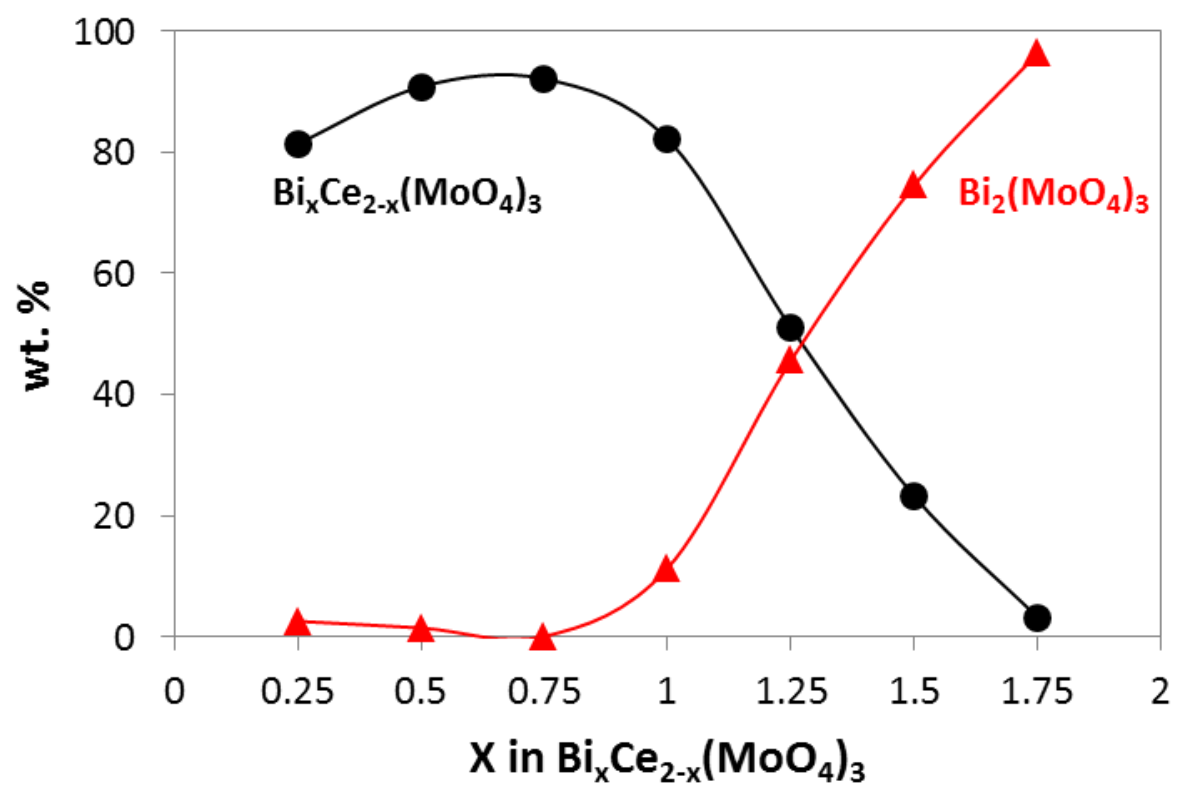

Figure 3a. Phase composition for the series $\mathrm{Bi}_{\mathrm{x}} \mathrm{Ce}_{2-\mathrm{x}} \mathrm{Mo}_{3} \mathrm{O}_{12} \mathrm{O} \leq \mathrm{x} \leq 2$.

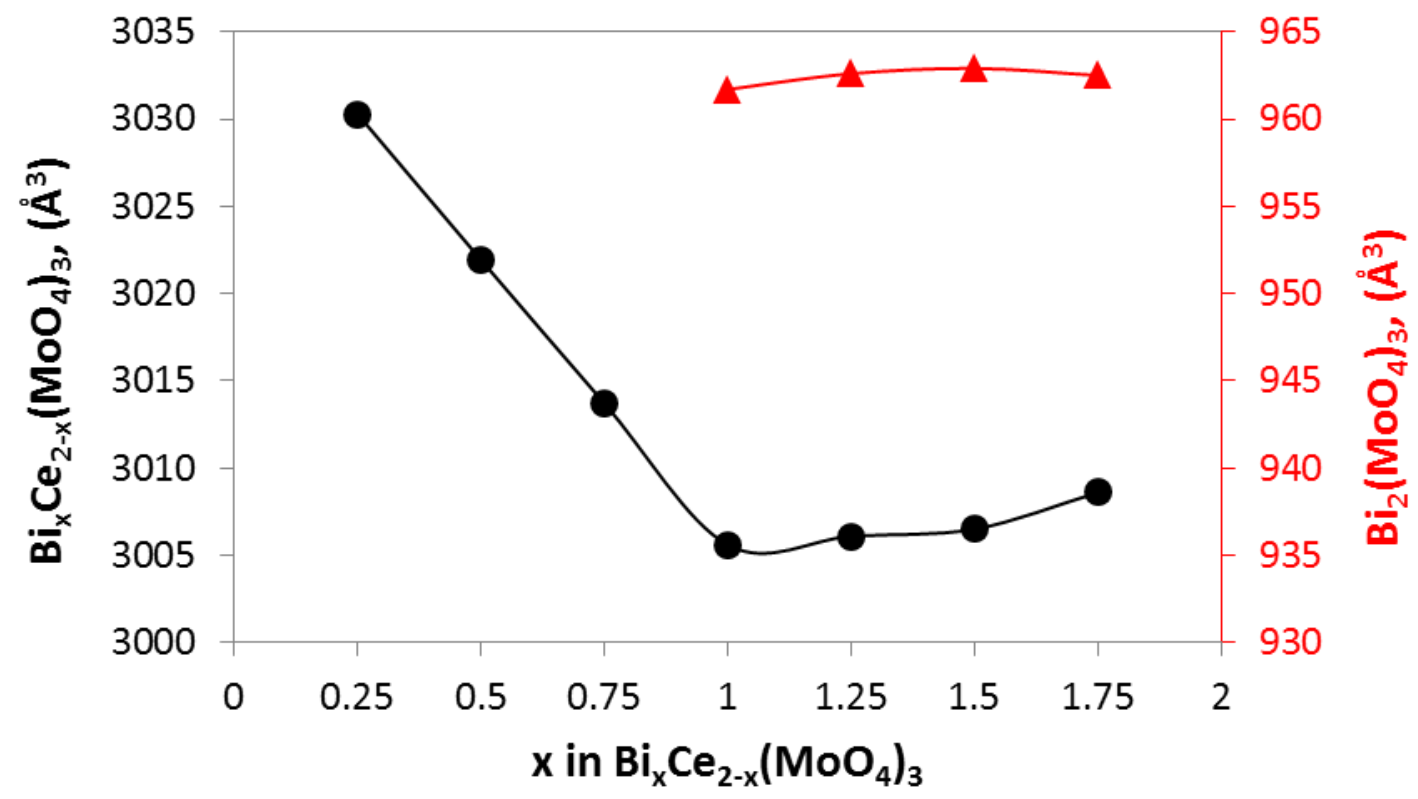

Figure 3b. Unit cell volumes for the series $\mathrm{Bi}_{\mathrm{x}} \mathrm{Ce}_{2-\mathrm{x}} \mathrm{Mo}_{3} \mathrm{O}_{12} 0 \leq \mathrm{x} \leq 2$. 


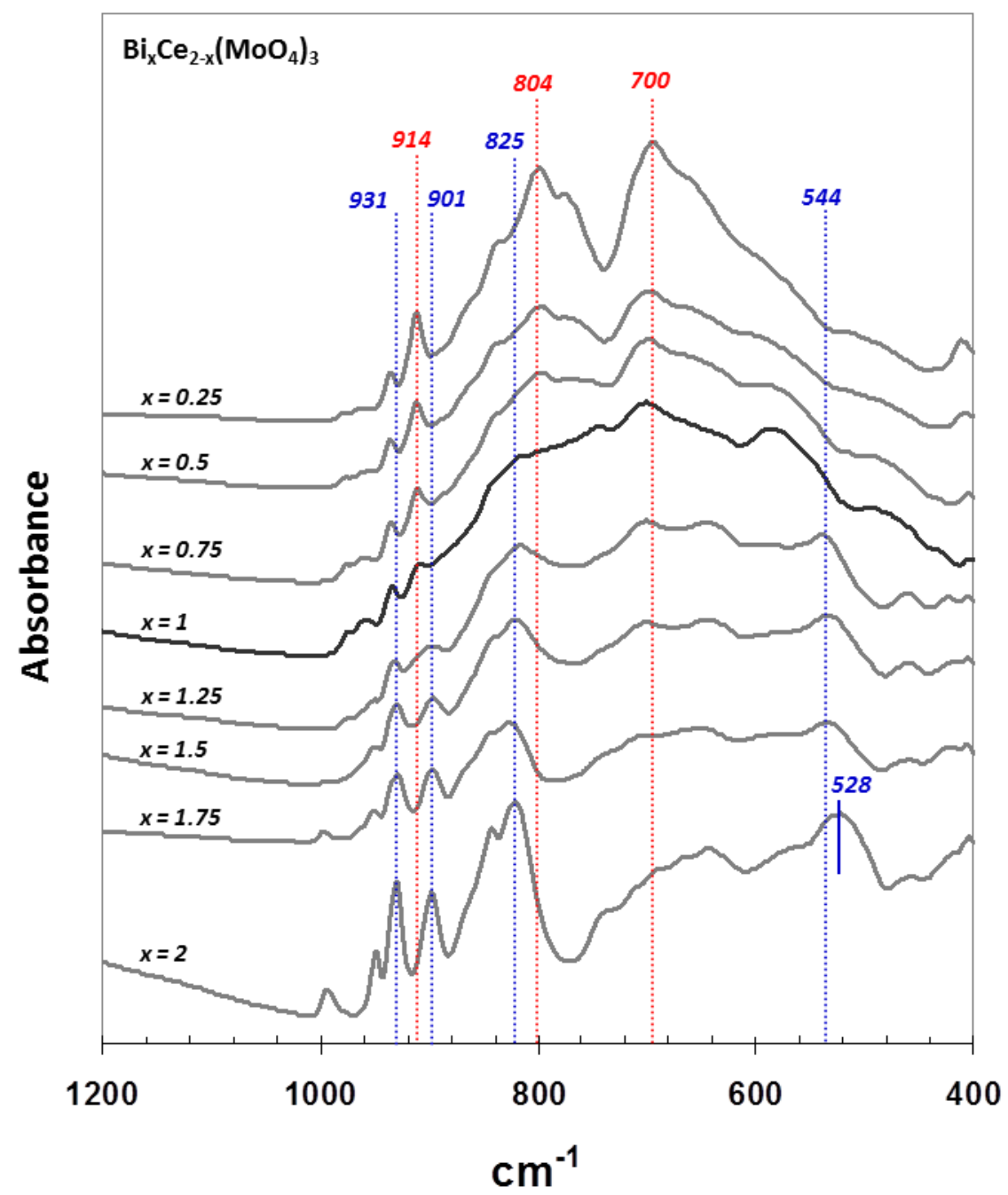

Figure 4. FTIR spectra for the series $\mathrm{Bi}_{\mathrm{x}} \mathrm{Ce}_{2-\mathrm{x}} \mathrm{Mo}_{3} \mathrm{O}_{12} \mathrm{O} \leq \mathrm{x} \leq 2$. 


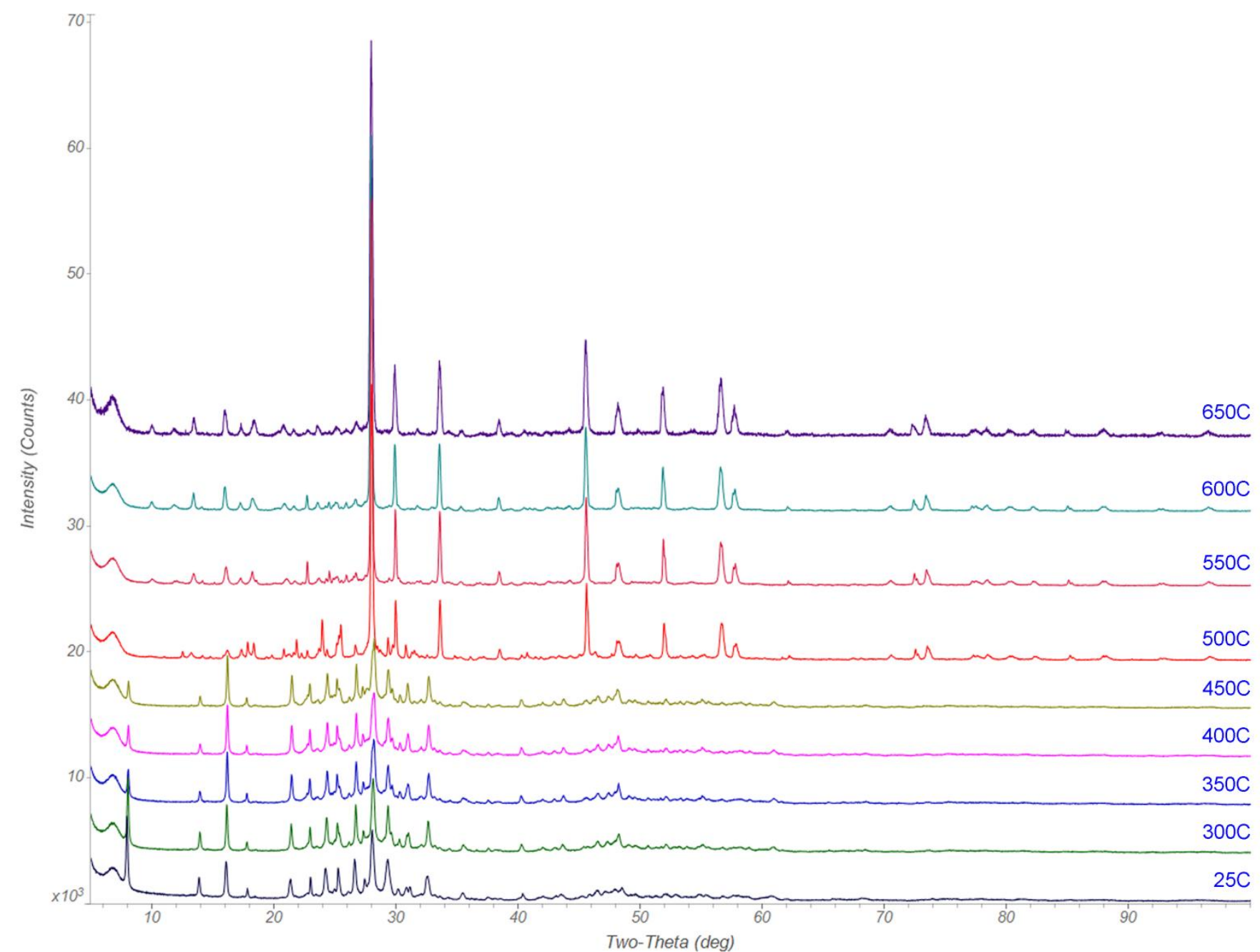

Figure 5. X-ray diffraction patterns for the composition $\mathrm{Bi}_{0.5} \mathrm{Ce}_{1.5} \mathrm{Mo}_{3} \mathrm{O}_{12}$ as a function of heat treatment temperature. 

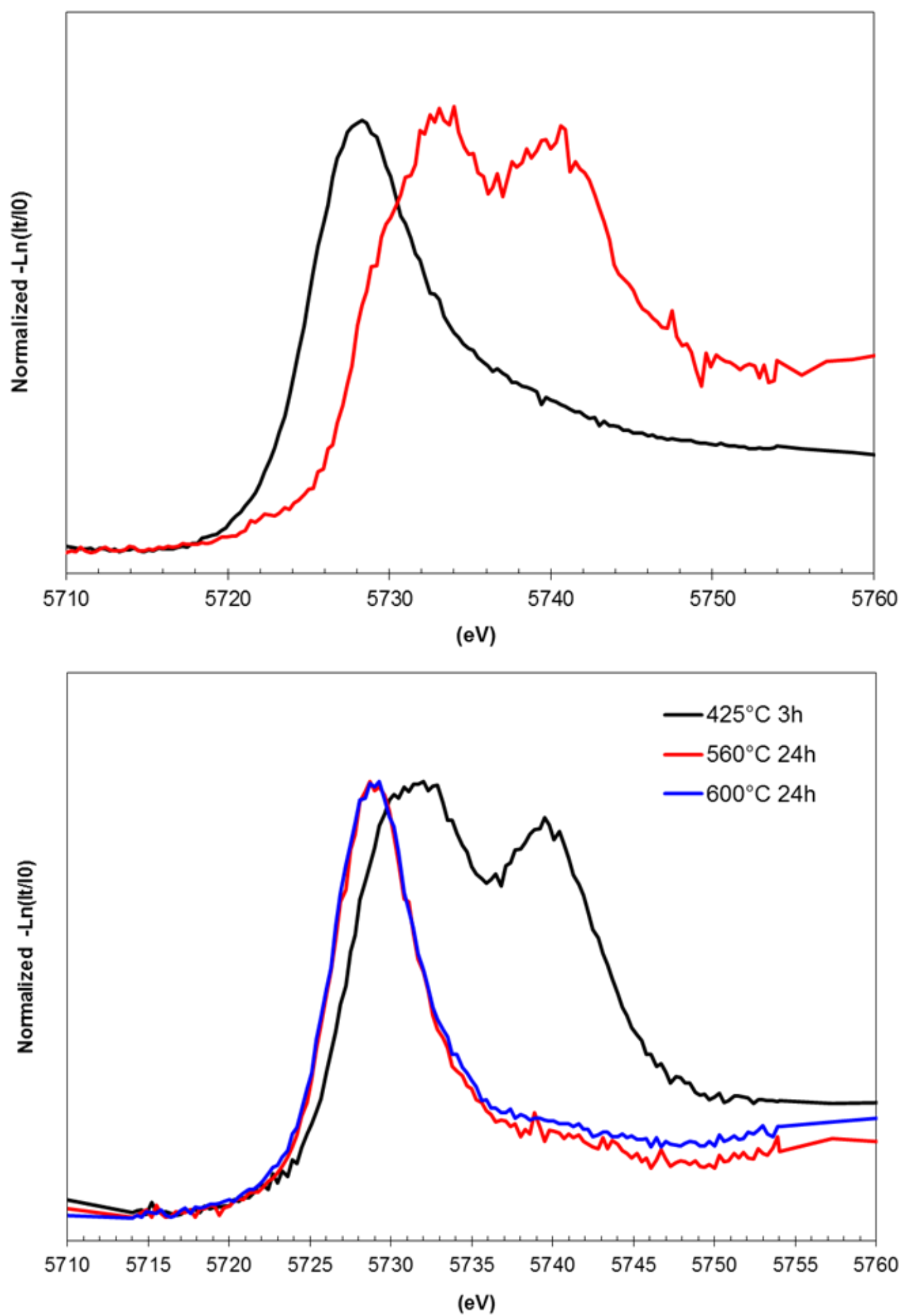

Figure 6. X-ray absorption near-edge structure (XANES). Top: $\mathrm{Ce}^{4+}$ and $\mathrm{Ce}^{3+}$ reference compounds $\mathrm{CeO}_{2}$ (red trace) and $\mathrm{Ce}_{2} \mathrm{~S}_{3}$ (black trace). Bottom: a sample of composition $\mathrm{Bi}_{0.5} \mathrm{Ce}_{1.5} \mathrm{Mo}_{3} \mathrm{O}_{12}$ after the indicated heat treatment temperatures. 


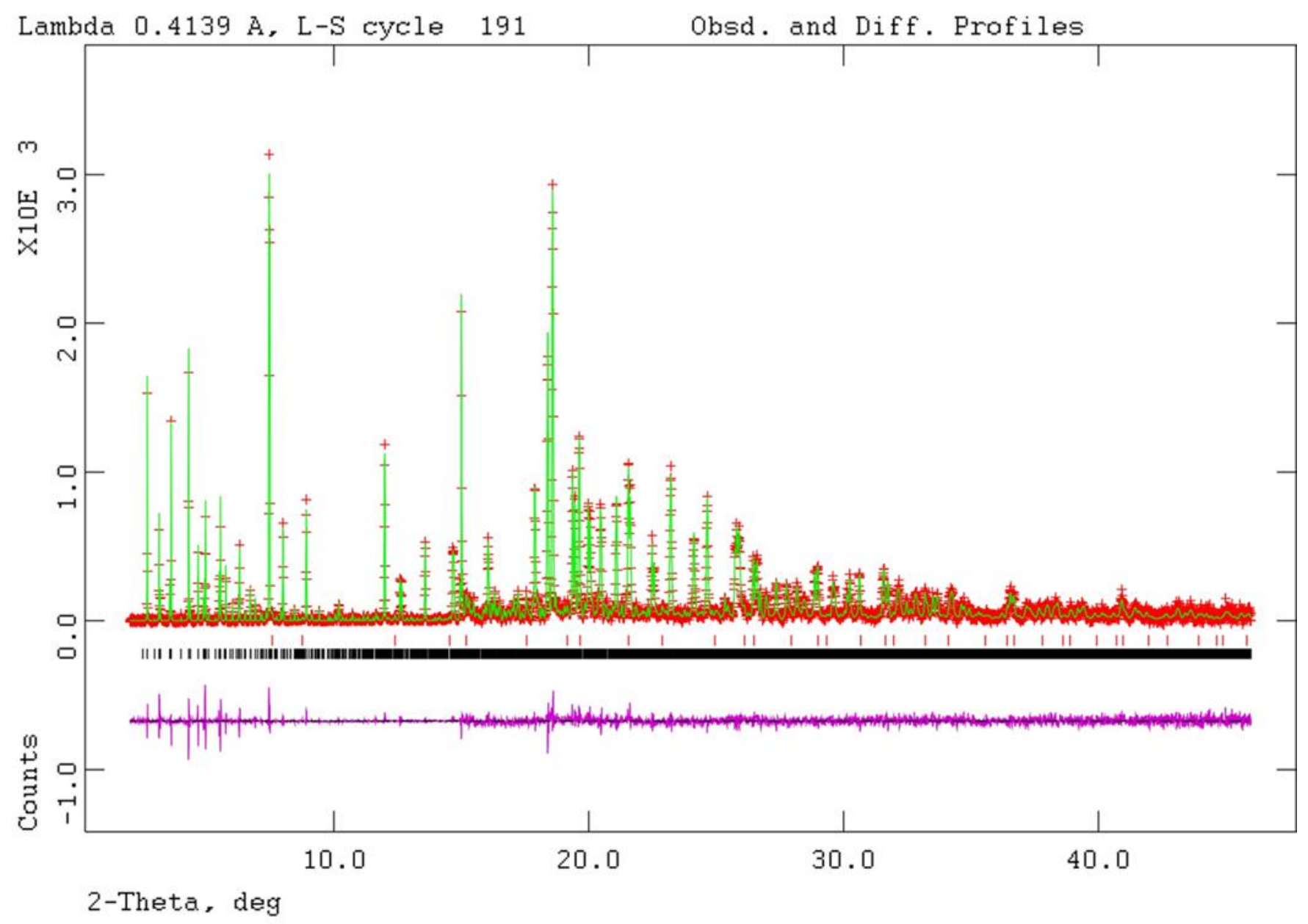

Figure 7. Rietveld refinement of the $\mathrm{X}$-ray diffraction pattern for the composition $\mathrm{Bi}_{0.5} \mathrm{Ce}_{1.5} \mathrm{Mo}_{3} \mathrm{O}_{12}$. Red points are observed data, green is the diffraction pattern for monoclinic cerium molybdate, and the pink trace at the bottom is the difference pattern between the two diffraction patterns. The vertical scale of the pattern below $7^{\circ}$ and about $15^{\circ}$ two-theta has been increased to better show the less intense diffraction peaks in those regions. 


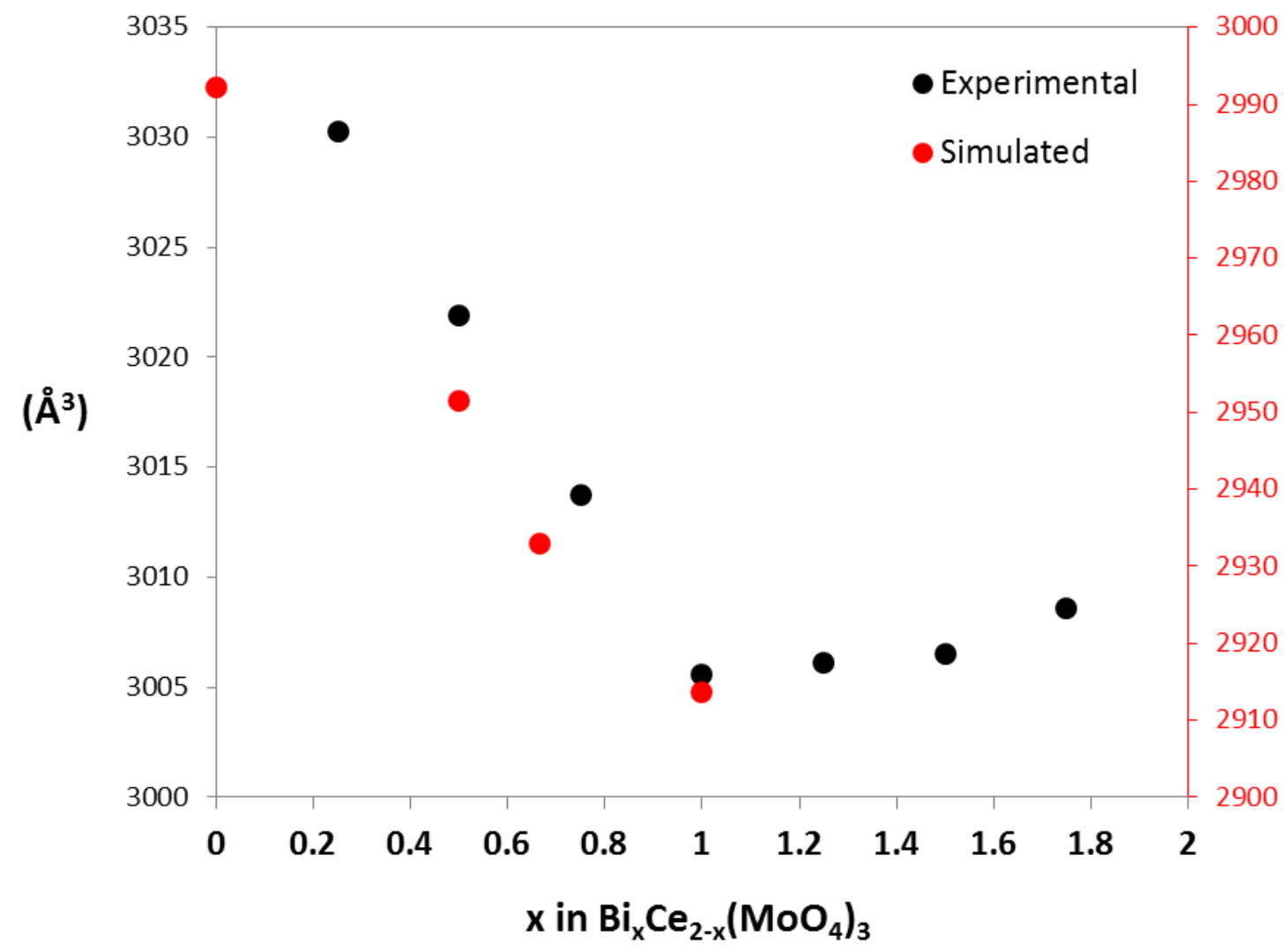

Figure 8. Unit cell volume for the series $\mathrm{Bi}_{\mathrm{x}} \mathrm{Ce}_{2-\mathrm{x}} \mathrm{Mo}_{3} \mathrm{O}_{12} \mathrm{O} \leq \mathrm{x} \leq 2$ as determined from model simulation compared to experiment. 

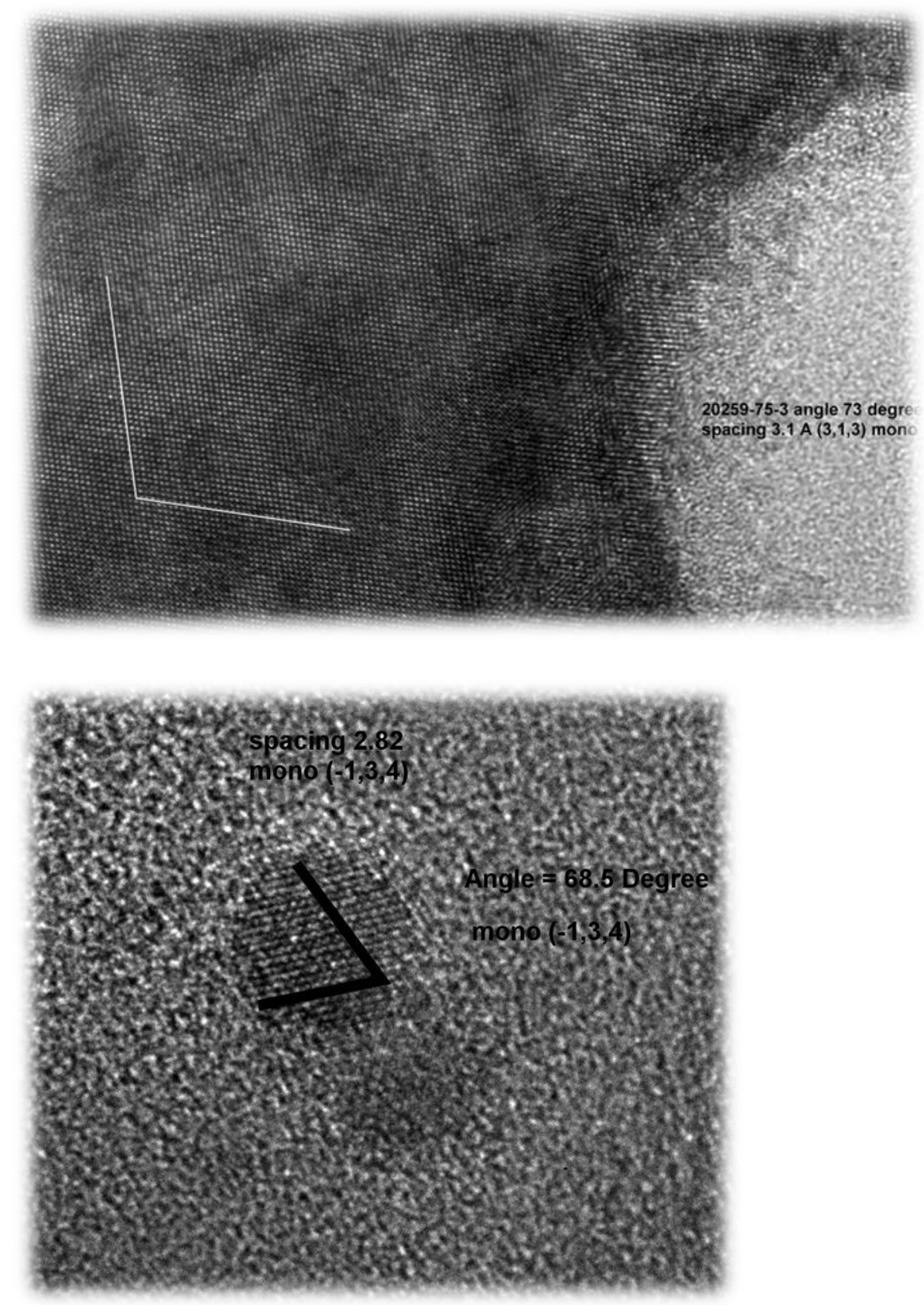

Figure 9. Transmission electron microscopy of $\mathrm{Bi}_{0.5} \mathrm{Ce}_{1.5} \mathrm{Mo}_{3} \mathrm{O}_{12}$. 


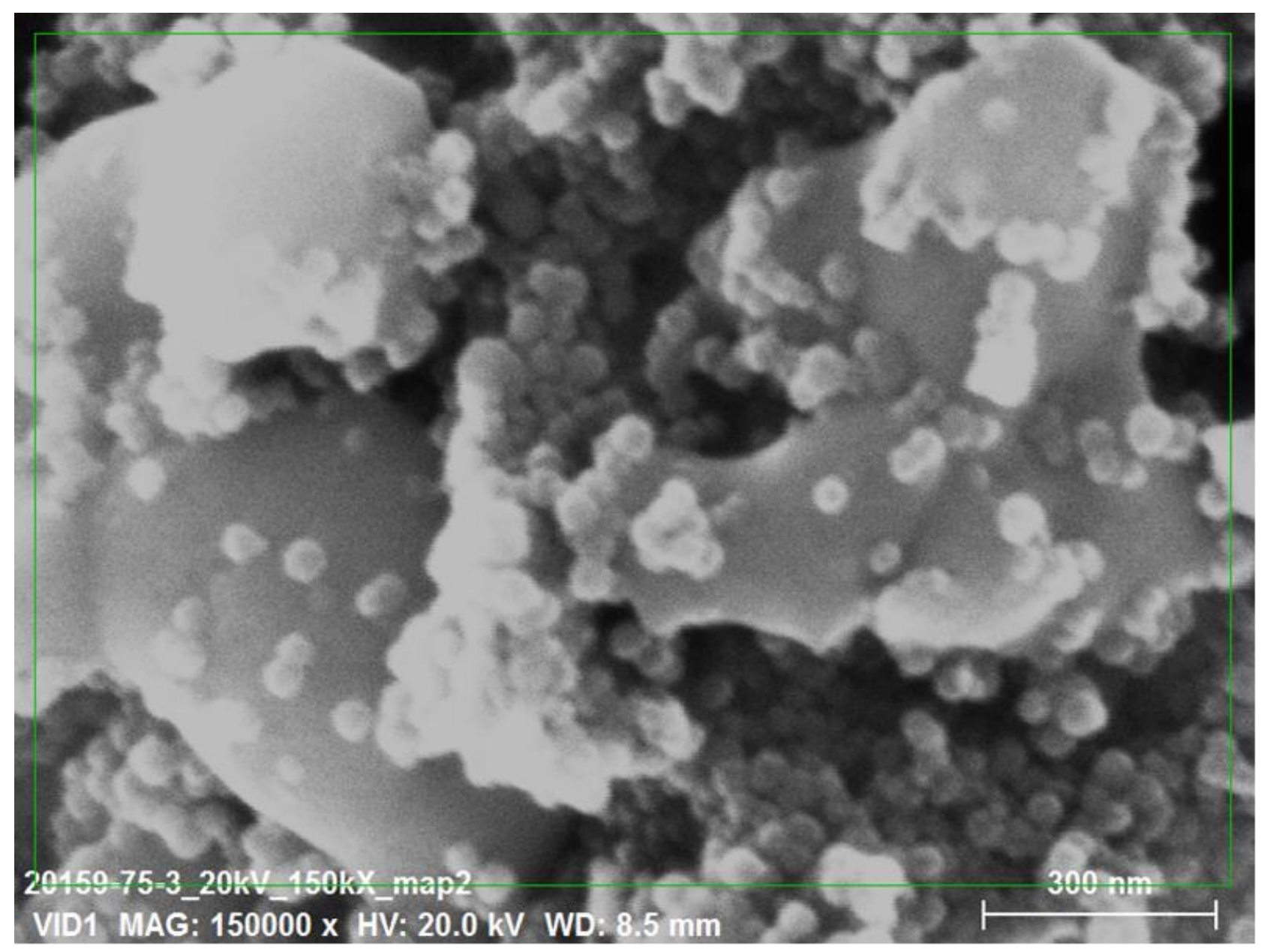

Figure 10. Scanning electron micrograph at $150 \mathrm{kX}$ magnification (Zeiss In-Lens + SEI detection) of silica supported $\mathrm{Bi}_{0.5} \mathrm{Ce}_{1.5} \mathrm{Mo}_{3} \mathrm{O}_{12}$. 


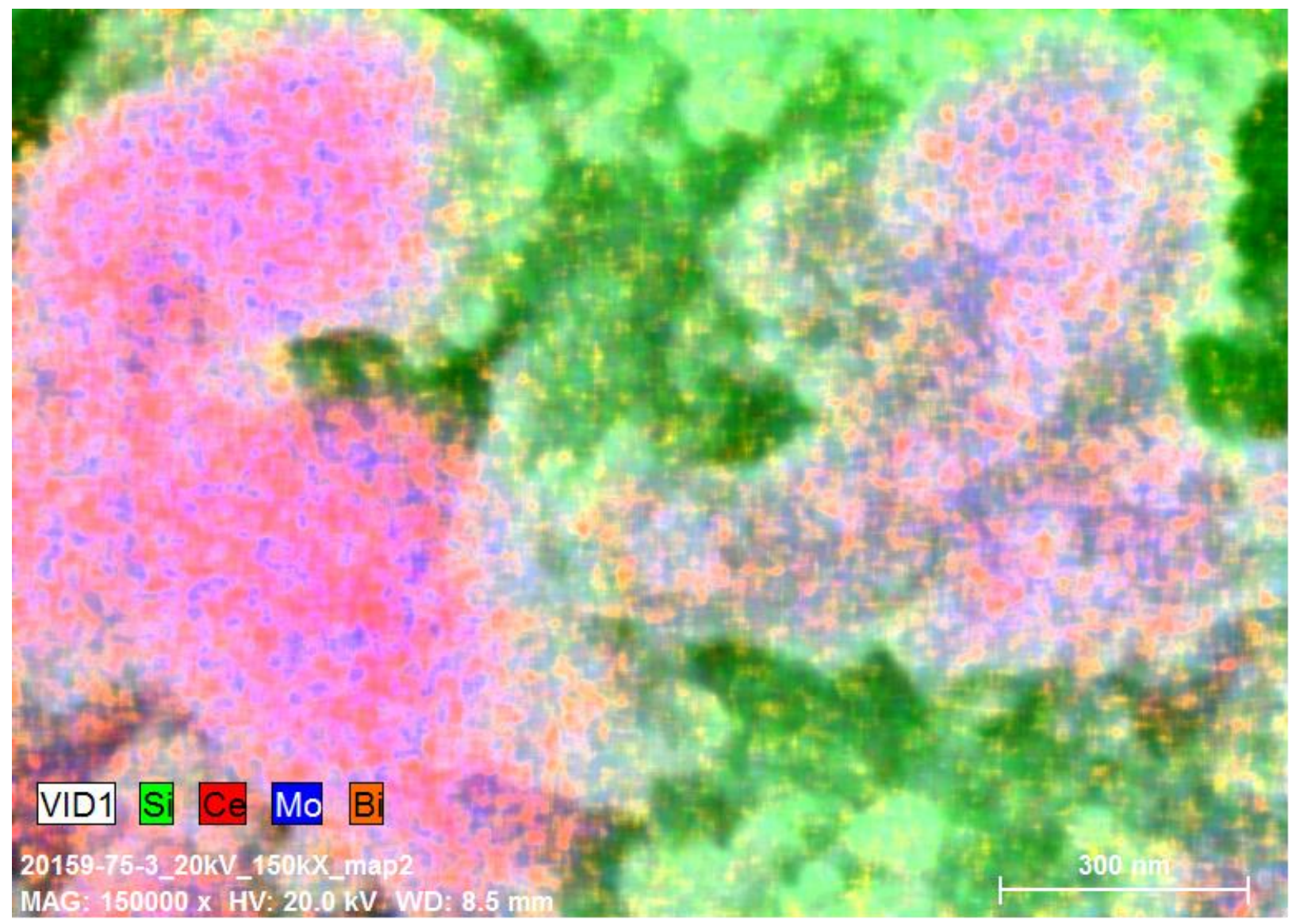

Figure 11. Si K $\alpha$, Ce $\mathrm{L} \alpha$, Mo $\mathrm{L} \alpha$ and $\mathrm{Bi} \mathrm{L} \alpha$ emission maps $-\mathrm{Ce}$ and $\mathrm{Bi}$ maps for the nominal composition $\mathrm{Bi}_{0.5} \mathrm{Ce}_{1.5} \mathrm{Mo}_{3} \mathrm{O}_{12}$. 


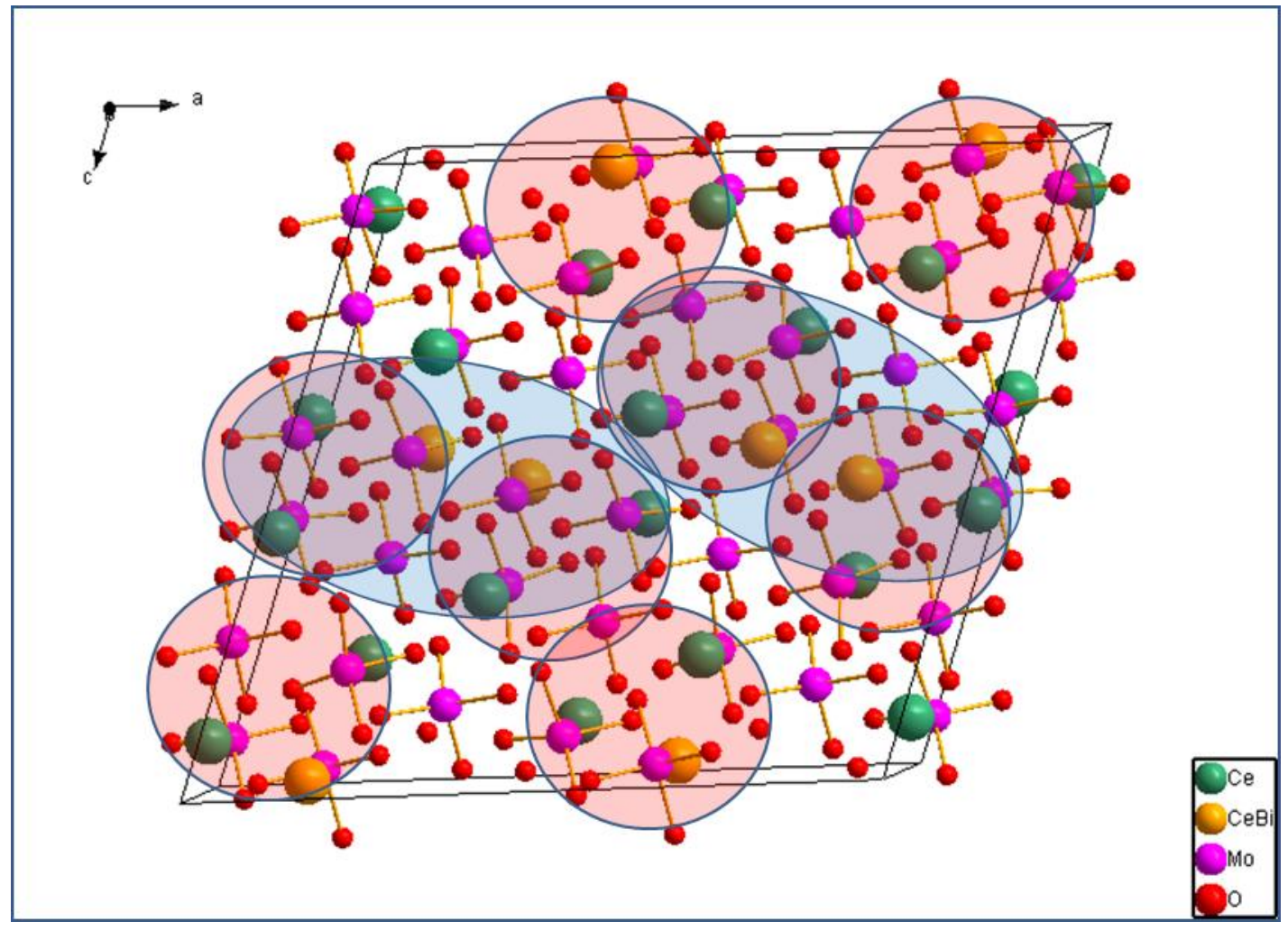

Figure 12. Model of active sites for propylene ammoxidation in bismuth-cerium molybdate solid solution having the cerium molybdate structure. 


\section{References}

[1] J. L. Callahan, R. K. Grasselli, E. C. Milberger, H. A. Strecker, Ind. Eng. Chem. Prod. Res. Dev. 9 (1970) 134-142.

[2] J. D. Idol, Jr., U.S. Patent No. 2,904,580 (1959).

[3] P. Mars, D. W. van Krevelen, Chem. Eng. Sci. (Spec. Suppl.) 3 (1954) 41-57.

[4] J. F. Brazdil, M. A. Toft, Ammoxidation in Encyclopedia of Catalysis, John Wiley \& Sons, Inc., 2010. pp. 1-62.

[5] J. F. Brazdil, D. D. Suresh, R. K. Grasselli, U.S. Patent No. 4,746,753.

[6] J. F. Brazdil, R. K. Grasselli, R. K., J. Catal. 79 (1983) 104-117.

[7] R. G. Teller, J. F. Brazdil, R. K. Grasselli, R Thomas, L. Corliss, J. Hastings, J. Solid State Chem. 52 (1984) 313-319.

[8] J. F. Brazdil, R. G. Teller, R. K. Grasselli, E. Kostiner in R. K. Grasselli, J. F. Brazdil, (Eds.), Solid State Chemistry in Catalysis, ACS Symposium Series No. 279, (1985) pp. 57-74.

[9] W. Jeitschko, Acta Cryst. B29 (1973) 2074-2081.

[10] P. L. Lee, D. Shu, M. Ramanathan, C. Preissner, J. Wang, M. A. Beno, R. B. Von Dreele, L.

Ribuad, C. Kurtz, S. M. Antao, X Jiao, B. H. Toby, J. Synch. Rad. 15 (2008) 427-432.

[11] J. Wang, B. H. Toby, P. L. Lee, L. Ribaud, S. M. Antao, C. Kurtz, M. Ramanthan, R. B. Von

Dreele, M. A. Beno, Rev. Sci. Inst. 79 (2008) 085105.

[12] A. C. Larson, R. B. Von Dreele, Los Alamos National Laboratory Report LAUR (2004) 86-784.

[13] B. H. Toby, J. Appl. Cryst. 34 (2001) 210-221.

[14] F. Shang, P. Wang, J. Koberstein, S. Khalid, S.W. Chan, Surface Science 563 (2004) 74-82.

[15] G. Kresse, J. Furthmüller, Phys. Rev. B $54 \underline{16}$ (1996) 11169-11186.

[16] G. Kresse, D. Joubert, Phys. Rev. $59 \underline{3}$ (1999) 1758-1775.

[17] J. Hafner, Journal of Computational Chemistry 29 (2008) 2044-2078.

[18] L. H. Brixner, A. W. Sleight, M. S. Licis, J. Solid State Chem. 5 (1972) 247-249.

[19] R. D. Shannon, Acta Cryst. A32 (1976) 751-767.

[20] B. Grzybowska,J. Haber, J. Komorek, J. Catal. 25 (1972) 25-32.

[21] A. Skliarov, Yu. Maximov, L. Ya. Margolis, O. V. Krylov, J. Catal. 39 (1975) 286-293.

[22] I. Matsuura, R. Schut, K. Hirakawa, J. Catal. 63 (1980) 152-166.

[23] T. L. Barr, C. G. Fries, F. Cariati, J. C. J. Bart, N. Giordano, J. Chem. Soc. Dalton Trans. 9 (1983) 1825-1829.

[24] Q. Huang, J. Xu, W. Li, Solid State Ionics 32/33 (1989) 244-249.

[25] J. D. Burrington, C. T. Kartisek, R. K. Grasselli, J. Catal. 87 (1984) 363-380. 